\section{What EDF Wants}

\section{To the Editor:}

In recent columns, Bio/Technology commentator Russ Hoyle has misrepresented a central point of the Environmental Defense Fund's (EDF's) proposal to FDA last October for the safety testing and labeling of genetically engineered foods, and has also misstated EDF's motivation for writing the proposal (Bio/Technology9:1039 and 10:958-959).

Contrary to Mr. Hoyle's reading of A Mutable Feasl: Assuring Food Safety in the Era of Genetic Engineering, we have not called on FDA to require that " allfoods derived from recombinant DNA technology . . . receive pre-market FDA approval as food additives" (emphasis added).

We have called for FDA to regulate substances added to foods through genetic engineering under the same Food Drug and Cosmetic Act (FDCA) requirements that apply today to chemical substances added to foods through more conventional means. At least in principle, FDA appears to agree with this approach (see letter from FDA's James Maryanski, Bio/Technology10:830).

The Food Additive Amendment to the FDCA deems a food "adulterated" if it contains an added substance, unless either (a) the FDA has approved the safety of the substance by issuing a specific food additive regulation or (b) the substance is "generally regarded, among experts qualified by scientific training and experience to evaluate its safety, as having been adequately shown through scientific procedures ... to be safe under its intended use," in other words, "GRAS." (21 U.S.C. Sec. 321.)

In A Mutable Feast, EDF urged FDA to regulate as food additives or as GRAS substances most expression products of interspecific and synthetic genetic material added to food organisms. Thus, where such an expression product in a genetically engineered food meets FDA's requirement for GRAS status-i.e., where published scientific literature shows the substance to be safe under its intended use-no food additive petition would be needed.

Mr. Hoyle accuses us of "sophistry" for asserting that there is no general scientific basis for presuming that genetically engineered foods will be safe to eat. In fact, by ignoring the context of our assertionour regulatory proposal under the FDCA-Mr. Hoyle himself spins manipulative logic. We argue simply that substances added to foods by genetic engineering ought to be judged according to the same legal presumption as substances added to foods by any other means: they are guilty until proven innocent.

Mr. Hoyle also argues that we are motivated largely by the Ltryptophan tragedy, in which ingestion of an unregulated genetically engineered food supplement claimed at least 27 lives for reasons that remain unknown. In fact, had this tragedy never occurred, our recommendations to FDA would remain the same. We want FDA to apply well established food safety requirements to genetically engineeered foods, rather than to give producers of these products special regulatory relief.

Rebecca J. Goldburg

D. Douglas Hopkins

Environmental Defense Fund

257 Park Avenue South

New York, NY 10010

\section{Revising the Revision of Genetically Modified Plant Oversight}

To the editor:

In their article ("Revising Oversight of Genetically Modified Plants," Bio/Technology 10:967-971, September) Huttner et al. correctly point out that USDA/APHIS is on shaky ground scientifically by justifying regulation of genetically engineered plants because the vectors and promoters used in transformation are derived from plant pathogens. It is generally understood that these vectors and promoters do not themselves contain the genes that cause pathogenicity and do not confer pest characteristics to the modified plants. The seeminglyfaultyreasoningwasnecessitated by the Administration's decision in the mid-1980s to oppose new legislation to regulate environmental release of genetically engineered organisms. Instead, federal agencies had to justify their jurisdiction over the new technology with existing legislation such as the Federal Plant Pest Act, which was created before genes were cloned. The authors also rightly point out that the key issues in assessing the risk posed by environmental release are based on the characteristics of the transgenic plants and an analysis of their interactions with other organisms and the environment.

Rather than subjecting proposed field tests to extensive environmental assessment, as the authors suggest, in reality the environmental assessments prepared by APHIS are nearly clones of one another. By focusing on the source of the DNA used in transformation, which has been almost always the same for the vast majority of transgenic plants, APHIS's environmental assessments provide little help in determining the real risk of release. In a recently published article ${ }^{1}$ we, along with a colleague, reviewed 41 environmental assessments prepared by APHIS. We found that the important issues involved in determining the potential impact of transgenic plants on other organisms and the environment, 